\title{
OS DESAFIOS DO PROCESSO COLETIVO BRASILEIRO
}

\author{
THE CHALLENGES OF THE BRAZILIAN COLLECTIVE PROCESS
}

LOS DESAFÍOS DEL PROCESO COLECTIVO BRASILEÑO

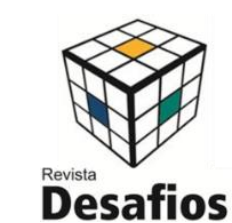

Marina Nogueira Madruga ${ }^{* 1}$, Rogério Raymundo Guimarães Filho**2

${ }^{1}$ Centro de Ciências Sociais e Tecnológicas, Programa de Pós-Graduação em Política Social e

Direitos Humanos, Universidade Católica de Pelotas, Pelotas-RS, Brasil.

${ }^{2}$ Programa de Pós-Graduação em Direito, Universidade Federal de Pelotas, Pelotas-RS, Brasil

Correspondência: e-mail:marina_mad@hotmail.com**rogerioguimar@yahoo.com.br

Artigo recebido em 27/07/2020 aprovado em 11/11/2020 publicado em 17/03/2021.

\section{RESUMO}

Este estudo é escrito com o objetivo geral de evidenciar os desafios do processo coletivo brasileiro na esfera jurídica. A partir de uma pesquisa bibliográfica, buscou-se descrever as necessidades para aplicação desse mecanismo processual cível, razão pela qual, apontam-se recomendações, pelos doutrinadores e por juristas nacionais - com base no Relatório Analítico Propositivo do CNJ, de 2018 - do que há de ser feito para proteção dos direitos massificados, bem como, apresentam-se os fatores que impedem sua aplicação. Nesse diapasão, aproveita para demonstrar a transição entre o Código de Processo Civil de 1973 para o Código de Processo Civil de 2015, salientando o enraizamento do Estado Social e a valorização da tutela de massas. Como resultado, destaca-se que o artigo não pretende solucionar as demandas do trato coletivo, mas "jogar luz" para que se tornem manifestas, a fim de concluir pela necessária revista dos institutos processuais cíveis para acompanhar a constante renovação das relações humanas, em prol da tutela de interesses coletivos.

Palavras-chave: Processo Coletivo. Direitos sociais. Desafios

\section{ABSTRACT}

This study is written with the general objective of highlighting the challenges of the Brazilian collective process in the legal sphere. From a bibliographic research, we sought to describe the needs for application of this procedural mechanism, which is why recommendations are made by national scholars and jurists - based on the 2018 CNJ Propositional Analytical Report - of what there is. to be done to protect mass rights, as well as the factors that prevent their application. On this tuning fork, he takes the opportunity to demonstrate the transition from the 1973 Civil Procedure Code to the 2015 Civil Procedure Code, underlining the rooting of the welfare state and the appreciation of mass protection. The article is not intended to solve the demands of collective bargaining, but to "shed light" so that they become manifest, in order to conclude by the necessary review of civil procedural institutes to accompany the constant renewal of human relations, in favor of the protection of collective interests.

Keywords: Collective process. Social rights. Challenges.

\section{RESUMEN}

Este estudio está escrito con el objetivo general de resaltar los desafíos del proceso colectivo brasileño en la esfera legal. Con base en una búsqueda bibliográfica, buscamos describir las necesidades para la aplicación de este mecanismo procesal civil, razón por la cual los expertos legales nacionales y expertos legales hacen recomendaciones, basadas en el Informe Analítico Propositivo CNJ 2018, que debe hacerse para proteger los derechos de masas, así como los factores que impiden su aplicación. En este diapasón, aprovecha la oportunidad 
para demostrar la transición del Código de Procedimiento Civil de 1973 al Código de Procedimiento Civil de 2015, haciendo hincapié en el enraizamiento del Estado Social y la apreciación de la protección masiva. Como resultado, se enfatiza que el artículo no pretende resolver las demandas de la negociación colectiva, sino "arrojar luz" para que se manifiesten, a fin de concluir con la revisión necesaria de los institutos de procedimiento civil para acompañar la renovación constante de las relaciones humanas, en para la protección de los intereses colectivos.

Descriptores: Proceso colectivo. Derechos sociales. Desafios

\section{INTRODUÇÃO}

O legislador brasileiro coloca a par dos interessados a possibilidade de empregar instrumentos viáveis a defesa dos direitos não-individuais, visto que a contemporaneidade convive com conflitos de massa. Pela constante evolução do processo civil, se tem como meio factível de acesso à Justiça, para aquelas situações as quais o processo singular não é tutelável, a possibilidade de proposição do processo coletivo.

Dentro do desenvolvimento do direito processual coletivo, apresenta a transição do individualismo ao surgimento do novo paradigma processual, com a enriquecimento do ordenamento jurídico e possibilidade de economia processual.

Assim, o presente trabalho, além da introdução e considerações finais, estrutura-se a partir de um principal ponto de discussão, que busca expor os principais problemas e desafios que atingem o processo coletivo, como também, apresenta possíveis sugestões de aprimoramento, com base na pesquisa Relatório Analítico Propositivo do CNJ, de 2018.

Salienta-se que não se pretendeu esgotar o assunto nem revolver a questão da tutela massificada do direito brasileiro, contudo, pretende tornar visível algumas das principais demandas do processo coletivo, a fim de contribuir com seu desenvolvimento, renovação e aplicação no universo jurídico.

\section{MÉTODO}

A pesquisa exploratória que aponta os principais desafios do processo coletivo no campo jurídico utiliza o método bibliográfico como base, fazendo uso das principais referências doutrinárias nacionais, bem como de juristas que estudam o tema, além do Relatório Analítico Propositivo do CNJ, de 2018.

\section{DO INDIVIDUAL AO COLETIVO: $O$ SURGIMENTO DE UM NOVO PARADIGMA PROCESSUAL}

A vertente individual do processo civil tem sido insatisfatória e deficiente para abraçar os novos tipos de direitos, de alta proeminência social, cuja titularidade pertence ao todo. Deste modo, na atualidade se deslocou a litigiosidade particular para conflitos massificados.

Em relação a esse destroncamento, Artur Torres menciona que o Código de Processo Civil de 1973, tratou de adequar-se à realidade social do Código de Beviláqua, logo, por sua cultura e período histórico "ignorava-se a necessidade de organizar a prestação jurisdicional de forma a possibilitar sua realização na forma coletiva" (TORRES, 2013, p. 44).

Torres menciona o descompromisso do anterior Código Civil em utilizar-se de instrumentos para o trato coletivo, declarando que a realidade da época era relacionada ao ideal de liberdade, período em que se devia "assegurar proteção aos indivíduos contra a arbitrariedade do Estado, inimigo número um da sociedade" (TORRES, 2013, p. 45).

No mesmo sentido, Hugo Nigro Mazzilli assevera 
O código de 1973 é individualista, e não poderia ser diferente, pois é um código da época: ao seu tempo, a tutela coletiva ainda não tinha nem nascido entre nós. Apesar de tecnicamente bem concebido, o Código Buzaid não previa a tutela coletiva, que ainda não tinha sido alçada no Direito brasileiro à condição de uma realidade forense, como é hoje de sobejo. Então, é certo dizer que o código de 1973 é individualista. Mas [...] não é verdade que o Código de Processo Civil de 2015 seja voltado para o coletivo. Ele contemplou, sim, incidentes que tornariam as teses dos tribunais vinculantes para os juízes inferiores ou resolveriam lides repetitivas, mas omitiu totalmente a disciplina do processo coletivo. (MAZZILLI, 2015, p. 11.)

\section{Teori Albino Zavaski aponta que o CPC/73} "foi estruturado a partir da clássica divisão de tutela jurisdicional em tutela de conhecimento, tutela de execução e tutela cautelar" (ZAVASKI, 2007, p. 17). Nesse sentido, o aparelhamento processual "foi moldado para atender à prestação da tutela jurisdicional em casos de lesões a direitos subjetivos individuais, mediante demandas promovidas pelo próprio lesado" (ZAVASKI, 2007, p. 18).

O Código de 1973 não previa a possibilidade de ajuizamento de tutelas em massa, no entanto, Carlos Alberto de Salles declara que com o declínio do paradigma liberal de Direito e de Estado, o qual protegia apenas autonomias individuais, passa-se a reconhecer modernos direitos. (SALLES, 2017, p. 39)

O surgimento desses recentes direitos, de terceira geração, caracterizados pela solidariedade e transindividualidade, exigiu do direito processual civil pátrio uma reestruturação, a fim de acompanhar as necessidades comunitárias, visto que aparecem inclusive direitos tipicamente vinculados à sociedade de consumo e à economia de massa, padronizada e globalizada. (MARINONI; ARENHART; MITIIERO, 2015, p. 403)

O nascimento dos processos jurídicos coletivos devem ser entendidos no contexto do Estado Social, em que a noção do bem comum é a somatória das vontades individuais de cada interessado, portanto,
Sob esse novo paradigma o papel do Estado é exercido a partir de objetivos sociais ou políticas públicas, a serem alcançados independentemente, embora de maneira compatível, das esferas de autonomia individual. O Estado torna-se implementador de políticas públicas. É nessa perspectiva que a atividade jurisdicional do Estado volta-se para solução de conflitos de natureza coletiva, os quais em última análise, têm a ver com fazer valer aqueles objetivos sociais incorporados ao ordenamento jurídico (SALLES, 2017, p. 39).

O Relatório analítico propositivo Justiça Pesquisa, do Conselho Nacional de Justiça de 2018, explica a profunda transformação jurídica ocorrida nos países ocidentais ao longo do século XX, a qual altera o perfil do Estado e a concepção do Direito

Essa macro-mudança costuma ser definida como a passagem do "Estado liberal" baseado no Laissez-faire, para o "Estado de bem-estar social", o Welfare State. $\mathrm{Na}$ ordem jurídica liberal clássica, a titularidade de direitos e o acesso à prestação jurisdicional eram reconhecidos apenas aos indivíduos, os quais deviam ser capazes de identificar seus direitos e provocar o Judiciário a protegê-los quando necessário. Com as transformações da sociedade e a consequente complexidade das relações sociais, a concepção do Direito sofreu uma alteração radical, incluindo novas categorias de direitos voltados para a proteção e a promoção de benefícios sociais aos indivíduos, comunidades e grupos. Nesse novo contexto, ganha relevância, ao lado da preocupação com o amplo acesso à justiça e a efetividade dos direitos sociais, o problema relativo ao reconhecimento e à defesa dos interesses difusos e coletivos, que não se limitam a um titular específico, sendo, ao contrário, difundidos entre os membros da comunidade ou referentes a uma coletividade de pessoas (CNJ, 2018, p. 13).

Portanto, à margem do Código de Processo Civil de 1973, surge o conjunto processual coletivo brasileiro, responsável pela tutela de massas. Ensina Artur Torres que o conteúdo processual coletivo “[...] tem seu start, certamente a partir do contato de juristas nacionais com a doutrina professada por Mauro Cappelletti, no início da década de setenta, [...] que logrou pensar o processo coletivo em perspectiva 
distinta da clássica visão codicista." (TORRES, 2013, p. 47)

Luiz Guilherme Marinoni, acompanhado de Sérgio Cruz Arenhart e Daniel Mitidiero declaram

\begin{abstract}
Além da necessidade de um processo civil que pudesse dar conta de direitos transindividuais, percebeu-se que ele também deveria voltar-se aos direitos que podem ser lesados em face dos conflitos próprios à sociedade de massa. A sociedade moderna abre a oportunidade a situações em que determinadas atividades podem trazer prejuízos aos interessados de grande número de pessoas, fazendo surgir problemas ignorados nas demandas individuais. $\mathrm{O}$ risco de tais lesões, que afetam simultaneamente inúmeros indivíduos ou categorias inteiras de pessoas, constitui fenômeno cada vez mais amplo e frequente na sociedade contemporânea. Ora, se a sociedade atual é caracterizada por ser de produção e consumo de massa, é natural que passem a surgir conflitos de massa e que os processualistas estejam cada vez mais preocupados em configurar um adequado "processo civil coletivo" para tutelar os conflitos emergentes. (MARINONI; ARENHART; MITIIERO, 2015, p. 404)
\end{abstract}

Para Sérgio Arenhart o diploma percursor que aborda a tutela de interesses coletivos foi a Lei $n^{\circ} 4.717$ de 1965, denominada Lei de Ação Popular (ARENHART, 2003, p. 151). Gregório de Assagra Almeida apresenta a edição da Lei de Ação Civil Pública com consequente implementação do Código de Defesa do Consumidor, de 1990, como marco fundador da tutela grupal (ALMEIDA, 2003).

Inexiste no ordenamento jurídico pátrio um regramento único do processo coletivo, "impondo uma interpretação sistemática e lógica de diversas normas", compondo o que os autores chamam de microssistema (RAMPIN, 2011, p. 23). Artur afirma: "Diz-se, atualmente, que o Brasil possui um complexo sistema processual coletivo [...], sendo função da doutrina e da jurisprudência alinhá-lo aos declarados interesses do Estado Constitucional de Direito" (TORRES, 2013, p. $55)$.

Em relação ao microssistema processual grupal, Teori expõe que: "trata-se de um sistema com objetivos próprios (a tutela de direitos coletivos e a tutela coletiva de direitos), que são alcançados a base de instrumentos próprios (ações civis públicas, ações civil coletivas) fundados em princípios e regras próprios" (ZAVASCKI, 2007, p. 27).

Para explicar esse sistema coletivo, Ricardo de Barros Leonel aponta que "com a tendência evolutiva do processo coletivo acabam surgindo vários diplomas que se entrelaçam" (LEONEL, 2017, p. 123). Logo, se tem a Lei de Ação Popular; Lei de Ação Civil Pública; Lei de defesa das pessoas portadoras de deficiência; Lei de defesa dos investidores do mercado de valores imobiliários; Estatuto da criança e do adolescente; Código de defesa do consumidor; Lei de improbidade administrativa; Lei de defesa da ordem econômica e da livre concorrência; Legislação orgânica do Ministério Público; Lei de defesa da ordem urbanística; Estatuto do idoso; Estatuto de defesa do consumidor, entre outras.

Rodrigo Eugênio Silva afirma ter a Carta Magna permitido o acesso ao direito coletivo, visto que

[...] Sobreveio a Constituição Federal, no bojo da qual foram inseridas as primeiras normas de tutela coletiva. Assim, a Constituição de 88 trouxe um alargamento de conceito, de legitimados e de objeto da tutela coletiva. Em seu artigo 129, inciso III, por exemplo, consagrou a regra de que a ação civil pública também se destinaria à defesa do meio ambiente, do patrimônio público e social, e de outros interesses difusos e coletivos (SILVA, 2016, p. 38).

Embora o Código de Processo Civil de 2015 não tenha disciplinado a tutela grupal, ofereceu alternativas para situações que podem ser tratadas em âmbito coletivo. (LEONEL, 2017, p. 171) Destaca-se que ele "também se mostrou atento ao novo cenário de valorização da tutela coletiva, buscando trazer novos institutos e mecanismos capazes de avançar ainda mais neste tipo de tutela." (SILVESTRE; NEVES; GUSELLA, 2017) 
A pesquisa realizada pelo Conselho Nacional de Justiça conclui que

\begin{abstract}
A tutela de direitos se abriu à dimensão coletiva principalmente por meio de reformas processuais, que legitimaram novos agentes (estatais e sociais), introduziram novas formas de ação e novas regras de tramitação que alargaram o acesso à justiça no Brasil. $\mathrm{O}$ resultado inevitável dessa expansão foi a aproximação da justiça e de suas principais instituições com o campo das políticas públicas, nas mais diversas áreas. Chamados a intervir em políticas, pela via dos direitos difusos e coletivos, os operadores do Direito se viram diante de grandes e inesperados desafios. (CNJ, 2018, p. 211)
\end{abstract}

Assim, é cogente que se arquitetem meios adequados de proteção das situações de direito coletivo inerentes à sociedade hodierna, como o surgimento do fenômeno processual coletivo. A partir da nova vertente processual, indaga-se quais os desafios que irão surgir durante seu desenvolvimento da jurisdição brasileira.

\section{PRINCIPAIS DESAFIOS DO PROCESSO COLETIVO}

Com a globalização e o dinamismo atual, o movimento de evolução processual não encontra fim, visto observar o processo "como meio para a satisfação dos anseios sociais decorrentes das crises na vida, modifica-se e aprimora nas mesmas dimensões de evolução[...] das facetas da vida" (LEONEL, 2017, p. 571).

Portanto, o mecanismo jurídico evolui a fim de abraçar as novas necessidades coletivas e sociais, razão pela qual, doutrinadores lançam recomendações do que há de ser feito para proteção dos direitos massificados, bem como, relatam os fatores que impedem a aplicação do direito coletivo no país.

O Relatório analítico propositivo Justiça Pesquisa, do Conselho Nacional de Justiça de 2018 em exame sobre Ações Coletivas no Brasil, abriu espaço para os magistrados entrevistados apontarem quais os principais problemas das ações massificadas e a indicação de sugestões para saná-los. (CNJ, 2018, p. 141)

Quanto às complicações indicados, o maior número de magistrados que participou da entrevista apontou para à falta de celeridade, como consequência da multiplicidade de réus, os quais, geradores de excessos de incidentes e prazo e à complexidade do processo nos tipos de pedidos e instrução. Neste último destacam o formalismo e o aspecto burocrático da ação coletiva, seguido da ausência de legislação unificada e as controvérsias jurídicas. (CNJ, 2018, p. 143)

Também indicou-se como problema a dificuldade na execução e a pouca utilização do processo coletivo pelos legitimados, conforme expõe

\begin{abstract}
Mais especificamente, a demora, devido ao amplo âmbito de alcance das ações, o grande número de beneficiários, o despreparo das partes e a falta de estrutura para o acompanhamento da execução. Outro fator de dificuldade indicado foi a propositura de ações individuais para execução. Os magistrados também indicaram a ineficácia prática das ações, em virtude do descumprimento por entes públicos e da falta de estrutura judiciária para o acompanhamento do cumprimento. Apenas um magistrado indicou dificuldades na execução de decisões que envolvem políticas públicas devido ao impacto orçamentário que geram (CNJ, 2018, p. 141).
\end{abstract}

Ricardo de Barros Leonel, coaduna com a pesquisa, no que tange à pouca utilização da ação coletiva, destacando-se a predominância da cultura individual e maior propositura de ações pelo Ministério Público entre os legitimados. (LEONEL, 2017, p. 573) Notabiliza o CNJ como barreiras "a falta de treinamento dos magistrados e dos servidores para lidar com ações coletivas. Também indicaram a falta de apoio técnico ao juiz em casos de alta complexidade como um problema" (CNJ, 2018, p. 143).

O custo da prova pericial também é apontado como uma dificuldade, além da indicação de multiplicidade de processos paralelos com possibilidade de decisões em conflito. Outra questão é 
a ausência de publicidade das sentenças, dificuldade em produzir provas, resistência do Judiciário às ações massificadas e uso destas para fins políticos. (CNJ, 2018, p. 143)

$\mathrm{Na}$ mesma linha, Gregório Assagra de Almeida salienta a tímida atuação dos demais legitimados ativos, a resistência à atuação do Ministério Público e a resistência oferecida à concepção coletiva do direito processual como dificuldades. (ALMEIDA, 2003, p. 586)

Mais à frente, a pesquisa aponta "outros" contratempos, como

[...] a falta de instrumento para tutela de direitos contra obrigados múltiplos e não delimitáveis; a vedação do uso em matéria tributária (como nesta matéria há repetição de processos, o cabimento do instituto seria útil); o excesso de prerrogativas de entes públicos (em específico, o instituto da suspensão de liminar como problemático); a possibilidade de cumprimento provisório de sentença de primeiro grau, que geraria tumulto processual e decisões conflitantes; e decisões dos tribunais derrubada a imposição de astreintes. (CNJ, 2018, p. 144)

Por esse ângulo, apresenta os problemas das ações coletivas, elencados pelos magistrados, respectivamente na falta de celeridade e complexidade do processo; dificuldades na execução; pouca utilização; falta de estrutura e excesso de trabalho; custo da perícia; despreparo ou falta de cooperação das partes; falta de publicidade; dificuldade na produção das provas; resistência do judiciário; uso político; entre outros. (CNJ, 2018, p. 144)

É possível observar pela lista de estorvos narrados pelos operadores do direito a existência de sérias dificuldades na implementação e efetivação das ações coletivas no Judiciário nacional. Tais desafios precisam ser enfrentados, a fim de satisfazer os conflitos de massa, propiciando ampliação do acesso à Justiça.

\section{Inexistência de um Código Processual Coletivo}

Dentre os distintos óbices apontados pela doutrina, destaca-se a ausência de compilação normativa processual coletiva.

$\mathrm{O}$ que se tem sobre processo grupal são normas esparsas sobre o conteúdo, que se entrelaçam e mantem correlação. Ricardo de Barros Leonel aponta que: "É simplesmente um conjunto sistemático de regras destinado de normas, com peculiaridades, destinadas a fazer frente às adversidades inerentes à defesa dos interesses transindividuais em juízo, valendo-se complementar e subsidiariamente dos institutos e regras do processo civil clássico" (LEONEL, 2017, p. 143). Para Teori o sistema é rico e sofisticado para atender os conflitos coletivos da sociedade atual. (ZAVASCKI, 2007, p. 37)

Talita Rampin reconhece que "O desafio do direito processual civil moderno consiste em conviver com uma multiplicidade de fontes materiais e formais, hipercomplexidade normativa, estar que, quando não manejada adequadamente, obstaculariza a concretização dos direitos" (RAMPIN, 2011, p. 28).

Os doutrinadores que primam pela codificação das normas processuais coletivas, justificam-na pela segurança jurisdicional, pela insuficiência do atual sistema em atender as necessidades oriundas da demanda coletiva, pela uniformização do direito para tornar claro e evidente o objeto formal do processo.

Rodolfo de Camargo Mancuso conclui que

A inexistência, dentre nós, de um Código Processual Coletivo, propriamente dito, acarreta a necessidade do translado e aplicação, nas ações coletivas, de categorias processuais oriundas da jurisdição singular, e então coloca-se a questão de como fazer com segurança esse transbordo, considerando-se que cada qual desses planos jurisdicionais parte de pressupostos próprios e buscas distintas de finalidades (MANCUSO, 2007, p. 106). 
Em síntese, Henrique Gobbi salienta a necessidade de criação de um sistema legal específico que abranja as normas do processo de massa: "Contudo, há alguns problemas que urgem de solução, pois além de se ter esparco fomento e acesso a tais mecanismos pela sociedade, há a questão puramente processual pendente, tal como da regulamentação expressa acerca da execução de eventual sentença condenatória" (GOBBI, 2018). O autor defende a quebra do paradigma individual, visto o atual sistema não atender todas as necessidades coletivas.

Almeida conclui que

A codificação tem como principal vantagem a ordenação e a uniformização do sistema a ser codificado. Com isso, a codificação torna mais claro e evidente o objeto formal da respectiva área do Direito a ser codificada, de sorte a simplificar o sistema jurídico e a permitir a sua melhor compreensão. Ela facilita também a ordenação dos princípios e regras de interpretação e de aplicação do Direito no contexto da incidência da respectiva área codificada (ALMEIDA, 2003, p. 141).

Júlio Camargo de Azevedo conclui que o contemporâneo estágio do processo de massa

[...] se afigura oportuna e convenientemente maduro para que se leve adiante a codificação. Ademais, esta parece ser a melhor saída para adequar o objeto material do processo coletivo ao Estado Democrático de Direito, alinhando-o às garantias constitucionais. Neste passo, a codificação representa não só a chance de estruturação do processo coletivo brasileiro, mas também a de adequar seus institutos sob a ótica da teoria dos direitos fundamentais27. Aliás, esta parece ter sido justamente a vontade de nosso legislador constituinte, quando da inclusão dos direitos coletivos no Título II, Capítulo I, da Constituição Federal de 1988 (AZEVEDO, 2012, p. 128).

Logo, assinala a imperiosa urgência de união da sociedade jurídica pátria, a fim de solidificar as regras do processo coletivo. (AZEVEDO, 2012, p.
Gregório, apesar de votar na elaboração de um código de direito processual coletivo-social, reconhece que isso pode causar dificuldades

A possibilidade de engessamento do sistema; mitigação de conquista com retrocessos indevidos no plano dos avanços já obtidos no sistema pátrio tanto no plano constitucional quanto no plano infraconstitucional; a adoção de modelos estrangeiros incompatíveis com o sistema brasileiro; à burocratização do próprio sistema do direito processual coletivo, com a geração de incidentes indesejáveis que venham retardar a tutela jurisdicional coletiva com prejuízos aos interesses sociais; a vinculação com a concepção liberal individualista do CPC, o que poderá ocorrer com a elaboração de um código que não rompa com as amarras do referido diploma processual etc. (ALMEIDA, 2003, p. 84).

Nesse sentido, um dos principais desafios a ser enfrentado é a criação de um Código Processual Coletivo, que solidifique as normas esparsas que formam o chamado microssistema atual.

\section{Conversão da tutela individual em coletiva}

Importante destacar a perspectiva de converter a tutela particular em grupal, conforme proposta do artigo 333 do Código de Processo Civil de 2015. O referido dispositivo inauguraria a possibilidade de converter-se demanda individual em coletiva, desde que cumpridos certos pressupostos: "a) relevância social; e b) dificuldade de formação do litisconsórcio" (CAMBI; FOGAÇA, 2017).

No entanto, a Comissão de Juristas do Senado Federal optou por "Não incluir no novo Código, o processo coletivo, em tramitação no Congresso Nacional, bem como os processos e procedimentos previstos em leis especiais" (CAMBI; FOGAÇA, 2017).

Segundo José Roberto Sotero de Melo Porto declara
Uma simples frase que ofende três instituições fundamentais à democracia: o Legislativo, (que não andou mal, anteviu vários problemas e foi 
minucioso no tratamento); os legitimados, notadamente a Defensoria (que dispõe de um "verdadeiro termômetro de litigância", e o Judiciário, a quem caberia, tecnicamente, frear demandas temerárias, e não ao Executivo, em um juízo abstrato prévio (PORTO, 2016).

No mesmo sentido

[...] Perdeu-se a oportunidade de regulamentar a matéria no âmbito do Código de Processo Civil, local apropriado para disciplinar as relações entre o processo individual e coletivo. Portanto, vetar o artigo 333 do CPC/2015, sob o argumento de que a conversão das ações individuais em coletivas exigia disciplina própria, em outra lei, foi despropositado e demonstra uma ausência efetiva de fundamentos razoáveis para não adotar tal técnica processual já no NCPC. (CAMBI; FOGAÇA, 2017)

No entanto, enquanto o dispositivo que converta diretamente a demanda individual em coletiva não nasce no ordenamento pátrio, contenta-se com o incidente de demandas repetitivas, conforme dispõe Sotero "[...] entendo ser possível dar alguma sobrevida ao instituto da conversão. Assim, ao lançar mão do artigo 139, X, deve o magistrado fazer uma interpretação à luz do artigo 333 e seus incisos, para abranger aqueles direitos intermediários de que se falou, além da mera previsão exemplificativa de existirem demandas repetitivas" (PORTO, 2016).

No mesmo viés, concluem Eduardo Cambi e Marcos Fogaça

Além disso, apesar do veto ao incidente de coletivização, como é dever do juiz determinar o saneamento de vícios processuais (art. 139, inc. IX, CPC), o princípio da instrumentalidade recomenda que o magistrado, ao invés de indeferir a petição inicial por falta de condição da ação e resolver o processo sem julgamento de mérito (arts. 330, inc. I, e 485, inc. I, CPC), aplique, por analogia o disposto no artigo $9^{\circ}$ da Lei 4.717/65, com reforço do artigo 139, inc. X, do CPC, e oficie a um dos colegitimados para, querendo, prosseguir no curso da ação, com a possibilidade de aditar ou emendar a petição inicial, a fim de transformar a ação, inicialmente individual, em coletiva (CAMBI; FOGAÇA, 2017).
Deste modo, outro desafio é a criação de um dispositivo que possibilite a conversão direta da demanda de individual à coletiva, primando pela plena eficácia do instituto processual, a fim de impedir a multiplicação desmedida de processos simulares.

\section{Coisa julgada coletiva e cautela na transição de normas}

No que tange a coisa julgada, Rodolfo Mancuso afirma que a coletiva não pode dar-se no sistema restrito da coisa julgada individual, singular, porque no plano coletivo há necessidade de expansão até onde se estendam os contornos do interesse metaindividual (MANCUSO, 2007, p. 106).

Ada Pelegrini expõe que: “A própria configuração das ações ideológicas - em que o bem a ser tutelado pertence a uma coletividade de pessoas exige, pelo menos até certo ponto, a extensão da coisa julgada ultra partes" (PELEGRINI, apud MANCUSO, 2007, p. 108).

Destarte, há proposta de relativização da coisa julgada, visto que os interesses metaindividuais atuais de dividiram, em conflitos de diversa repercussão social, instante em que é inevitável a oferta de coisas julgadas diferentes e adaptadas a cada caso concreto, em prol da estabilidade, imutabilidade e indiscutibilidade. Nesse sentido, impossível aplicar-se ao direito coletivo o regime de coisa julgada próprio de lides intersubjetivas (MANCUSO, 2007, p. 107).

Marinoni e outros, sabiamente expõe: “[...] se o direito pertence a todos, realmente a solução da controvérsia sobre o direito deve abranger a todos, tornando-se a decisão imutável para as partes do processo e para as partes em sentido material" (MARINONI; ARENHART; MITIIERO, 2015, p. 408).

Antonio Gide observa: "Muitos problemas na aplicação do direito seriam causados se fizéssemos o 'transplante' puro e simples - sem as necessárias 
adaptações - do regime jurídico da coisa julgada nas ações individuais para as coletivas" (GIDE, apud MANCUSO, 2017, p. 111). No mesmo sentido, Rodolfo salienta a dificuldade de transposição das normas relativas as condições da ação, competência, perpetuatio jurisdictionis, entre outro. (MANCUSO, 2017, p. 115/118).

Assim, a transposição dos critérios e parâmetros do processo individual para a coisa julgada de massas se mostra inviável, visto que dada a natureza adjetiva dessa, não é ela quem produz efeitos substantivos, mas agrega a imutabilidade de seus comandos e efeitos, analisados pela razoabilidade.

Por conseguinte, imperioso relativizar e adaptar as lides coletivas, pois "o traslado de institutos e categorias da jurisdição singular nem sempre será possível ou seguro, devendo o intérprete e aplicador proceder com toda a cautela nesse transporte" (MANCUSO, 2017, p. 118).

\section{Resistência oferecida à concepção coletiva $\mathrm{e}$ apego as regras ortodoxas do $\mathrm{CPC}$ e do $\mathrm{CC}$}

Gregório de Assagra Almeida expõe ser forte no país a resistência quanto ao direito coletivo, com raízes políticas, sociais, jurídicas, econômicas e culturais. Ocasião em que demonstra o distanciamento da população por não lutar por direitos sociais (ALMEIDA, 2003, p. 586).

Ainda, o autor destaca que o operador do direito pátrio muito se apega ao Código de Defesa do Consumidor e Código Civil, na tentativa de resolver conflitos coletivos, no entanto, são normativas reguladoras dos conflitos individuais, concluindo que "tudo isso impede a aplicabilidade do direito processual coletivo" (ALMEIDA, 2003, p. 588).

Tais barreiras precisam ser vencidas, a fim de superar as regras ortodoxas liberais-individuais em busca de maior regramento compatível com o trato coletivo.

\section{Problema do ensino jurídico e currículos universitários}

Quanto a aplicação e interpretação da jurisdição coletiva, se tem que "a formação liberalindividualista do profissional do Direito no Brasil, em que grande parte durante sua vida acadêmica, é doutrinado a enfrentar somente conflito interindividual" (ALMEIDA, 2013, p. 587).

Gregório observa que o ensino jurídico não é apto a preparar seus operadores para enfrentar as inúmeras causas sociais, sendo a ciência do direito limitada pela dogmática, impedindo conhecimento multidisciplinar (ALMEIDA, 2013, p. 587).

Como principal motivo da crise jurídica vivenciada no país, Antônio Alberto Machado menciona a quantia de cursos de direito existentes e a falha nas grades curriculares. Nesse sentido, assegura

\begin{abstract}
Essa política de massificação do ensino jurídico explica também a natureza da grade curricular das faculdades de direito que tendem a privilegiar matérias e disciplinas tecnológicas, em detrimento daquelas que apresentam um conteúdo mais humanístico e reflexivo. Tais opções curriculares podem ser entendidas até mesmo como parte da estratégia de despolitização do jurista e atrofia de seu senso crítico" (MACHADO, apud ALMEIDA, 2013, p. 588).
\end{abstract}

Imperioso adequar as grades acadêmicas para abarcar disciplinas como meio ambiente, consumidor, tutelas jurisdicional coletiva, etc. Aliás, os estudantes de Direito devem enxergar os fundamentos do mundo jurídico, a fim de primar por convivência democrática, da função social e entender a necessidade de promover distribuição igualitária dos direitos fundamentais (ALMEIDA, 2013, p. 587).

O aprimoramento das grades curriculares no curso de Direito mostra-se necessário para que os operadores jurídicos consigam visualizar as demandas coletivas e se avance na compreensão e o desenvolvimento do direito processual coletivo. 


\section{Resistência à atuação do Ministério Público como legitimado ativo e tímida atuação dos demais legitimados}

O principal protagonista da tutela de massas é o Ministério Público. Sobre essa afirmação, Ricardo Leonel aponta haver duas faces

Por um lado, o reconhecimento de que o legislador formulou opções corretas ao dar à Instituição a configuração que ostenta, destinada à defesa, em juízo e fora dele, de todos os interesses dotados de relevância social. De outro, cria a expectativa da sociedade de que a Instituição assuma efetivamente esse papel (LEONEL, 2017, p. 574).

Gregório descreve que tanto a doutrina como a jurisprudência resistem à legitimação ativa do Parquet, baseada em "uma visão distorcida do papel do Ministério Público no atual cenário brasileiro" (ALMEIDA, 2013, p. 590).

Nota-se a equivocada ideia dos Tribunais em negar legitimidade ao órgão para a tutela de direitos massificados, visto que, conforme aponta Ricardo, o Ministério Público atua na tutela de interesses sociais em sentido amplo: "Ora, é interesse da sociedade a resolução de um mesmo processo de várias lides individuais. É interesse da sociedade que não haja na esfera jurisdicional muitas decisões conflitantes" (MANCUSO, 2017, p. 600).

No entanto, o órgão enfrenta resistências em sua atuação, um tanto coorporativas, conforme menciona Gregório. Há de conscientizar outros institutos de que a atuação do Ministério Público nas demandas grupais podem privilegiar interesses sociais necessários de proteção (ALMEIDA, 2013, p. 590).

Com sabedoria, Ricardo conclui que com a velocidade das mudanças na sociedade e surgimento de novos problemas, o Parquet terá nova função principal, qual seja a proteção dos interesses supraindividuais: "É um novo caminho a ser trilhado pelo Ministério Público. Não há necessidade de abandono das tradicionais funções na esfera cível ou na criminal, na qual se encontram seu nascedouro, as origens e a tradição da Instituição" (LEONEL, 2017, p. 575).

Portanto, o que se espera é "uma mudança de mentalidade da Instituição, a fim de tornar-se aberta e permeável à sociedade [...] além de ser dotada de instrumentos propícios ao aprimoramento da investigação, mormente quanto à prova técnica, que no processo coletivo é complexa e onerosa" (LEOLNEL, 2017, p. 575).

Verifica-se que os demais legitimados ativos não atuam como o Ministério Público na proposição de ações coletivas. Há, portanto, uma tímida atuação, o que demonstra fragilidade democrática participativa no Brasil.

Rodolfo expõe ser compreensível o Ministério Público assumir a posição principal, visto que

Não deixa de ser preocupante o fato de que a existência de uma democracia participativa, a par do apelo constitucional ao pluralismo na legitimação ativa para a ação civil pública $(\mathrm{CF}$, art. 129, III, parágrafo $1^{\circ}$ ) parece não ter seduzido os entes políticos, os quais vem passando ao largo desse poder-dever que lhes vem cometido inclusive em legislação infraconstitucional (MANCUSO, 2017, p. 601).

Há preocupação com a frágil democracia, na medida em que se revela elementar para a organização da sociedade para o trato coletivo, salientando a gravidade da crise educacional no país e a pouca consciência dos brasileiros em relação aos seus direitos fundamentais, gerando sentimento de impotência, frente aos direitos coletivos (LEONEL, 2017, p. 575).

\section{Possibilidade de aprimoramento nas ações coletivas}

Frente aos problemas destacados no processo coletivo e a necessidade de enfrentá-los, se tem também a desorganização do judiciário brasileiro, 
fator que impede o desenvolvimento da tutela coletiva: "Um dos grandes problemas referentes à efetividade do direito processual coletivo decorre do despreparo organizacional do Poder Judiciário para o enfrentamento de conflitos massificados" (ALMEIDA, 2013, p. 601).

Nessa perspectiva, Gregório propõe a criação de varas especializadas para o julgamento de lides de massa, bem como o aperfeiçoamento dos julgadores e apoio para pesquisa, orientação e matéria, por Órgãos Superiores da Justiça (ALMEIDA, 2013, p. 602). Na mesma linha, Ricardo posiciona-se a favor da criação das varas especiais e da melhora na estrutura técnica, além da implementação de serviços periciais (LEONEL, 2017, p. 574).

Como principal sugestão para o direito processual coletivo, o Relatório analítico propositivo Justiça Pesquisa, do Conselho Nacional de Justiça, do corrente ano, aponta a necessidade de criação de varas especializadas. (CNJ, 2018, p. 145)

A pesquisa elaborada pelo Conselho Nacional de Justiça obteve como fundamental sugestão a criação de varas especializadas para trato do direito coletivo,

Doze dos 45 magistrados que fizeram sugestões (26\%) apresentaram essa ideia. Em segundo lugar vem uma categoria que engloba sugestões relativas à sistematização única e a simplificação dos procedimentos. Onze magistrados $(24,4 \%)$ fizeram essa sugestão. Mais especificamente, sugeriram a adoção de capítulo sobre ações coletivas no CPC ou de Código de Processo Coletivo. Também sugeriram a adoção de acordo de leniência em ações de improbidade administrativa, bem como unificação desse tipo de processo nas esferas cível e penal. (CNJ, 2018, p. 145)

Outras sugestões englobam o incentivo ao uso de ações coletivas, conforme pesquisa realizada, aponta-se: a criação de um fundo para arcar com a antecipação de honorários das provas periciais técnicas; a adoção de instituto que estabeleça a suspensão das ações individuais até o julgamento de ação coletiva sobre a mesma questão, para evitar a multiplicidade de processos e o risco de decisões conflitantes; eliminar ou abreviar fases que julgam desnecessárias do processo (defesa prévia e a resposta preliminar em ações de improbidade administrativa); adoção de mecanismos, como convênios, que permitam a requisição de servidores técnicos especializados de outros órgãos públicos, como instituições de ensino superior, para a realização de perícias técnicas, e a adoção de procedimento licitatório para a contratação de peritos, que realizariam blocos de perícias; atribuir ao MP ou à Defensoria Pública, dependendo de quem é o autor da ação, o custo da prova pericial técnica. (CNJ, 2018, p. 146)

Também, destaca-se a adoção de mecanismos mais rígidos de responsabilização por descumprimento de sentença a adoção de instituto que estabeleça que a reunião de processos para julgamento em um só juízo, sem limite territorial; a execução de ações coletivas seja realizada administrativamente, não judicialmente e outras, como: "restringir a legitimidade para evitar uso do instituto com fins políticos; autorizar o controle jurisdicional sobre TACs; aprimorar a estrutura das defensorias públicas para que estejam em condições de instruir melhor as ações; e ampliar a legitimidade ativa para aumentar o uso" (CNJ, 2018, p. 146).

Ricardo de Barros Leonel propõe a discussão da legitimação do cidadão como uma perspectiva do direito coletivo, já que presente na ação popular. O autor declara que

[...] parece não haver motivo técnico, de lege ferenda, a impedir que o cidadão possa exercer a tutela judicial dos interesses metaindividuais relativos ao patrimônio público, ao meio ambiente, etc. não só quando seja responsável pela lesão o Poder Público, mas também quando o violador for particular, pessoa física ou jurídica. (LEONEL, 2017, p. 572)

Tal pressuposto, segundo Ricardo propiciará a ampliação do acesso à tutela coletiva, bem como uma 
maturidade política e democrática, salientando a necessidade de modos de aferição de representação adequada, bem como, responsabilização em casos de litigância temerária ou má-fé (LEONEL, 2017, p. 573).

Barros ainda propõe que os tribunais afastem as limitações à propositura da lide coletiva, pois tais barreiras prejudicam o acesso à justiça e caracterizamse pelo aumento significativo dos processos judiciais (LEONEL, 2017, p. 574).

Além disso, Gregório recomenda que se desenvolva "a ideia de uma teoria geral do direito processual coletivo, concebendo-a essencialmente sob o prisma constitucional, (...) instrumento fundamental e indispensável ao Estado Democrático de Direito" (ALMEIDA, 2013, p. 609).

Como possibilidades de aprimoramento, destaca Ricardo a "adoção de incidente de coletivização da tutela jurisdicional", como a conversão da tutela individual em coletiva, a publicidade das decisões a respeito do direito de massas e melhoria da fiscalização no cumprimento das decisões (LEONEL, 2017, p. 575).

Nota-se que os próprios magistrados que lidam com o direito cotidianamente entendem a necessidade de aprimorar o instituto da tutela coletiva, sugerindo mudanças que facilitariam $o$ desenvolvimento e alcance dos direitos de massa.

\section{CONCLUSÃO}

O objetivo do presente estudo foi compreender os principais problemas e perspectivas que envolvem a defesa de interesses de natureza coletiva. Neste diapasão, observa-se a constante evolução do fenômeno de intereresses supraindividuais, apontando as peculiaridades da transição do individualismo ao coletivismo, afastando-se do primeiro, em prol dos direitos massificados no Estado Social.
Em busca do atendimento das necessidades decorrentes da vida e o consequente surgimento de conflitos, batalha o direito processual civil pela pacificação social. Portanto, as principais tendências do processo coletivo são superar os problemas hodiernos, como: falta de celeridade; complexidade processual; dificuldades na execução; pouca utilização do processo de massas, entre outros.

Assim, surgem as sugestões dos doutrinadores para aperfeiçoamento desse instrumento que protege o coletivo, a fim de buscar efetividade aos novos direitos e enraizar contornos promocionais de natureza coletiva e social: teoria geral do direito processual coletivo; possibilidade de conversão da tutela individual em coletiva; cautela na transição das normas para o trato grupal e relativização da coisa julgada; desapegar-se das regras ortodoxas do CPC e CC; aprimorar os cursos jurídicos e suas grades curriculares, bem como, superar a atuação solitária do

Ministério Público como legitimado ativo, incentivando os demais à participação e implementação da ação coletiva.

À luz dos conflitos de massa, necessário a revista dos institutos processuais cíveis para acompanhar a constante renovação das relações humanas, em prol da tutela de interesses coletivos.

\section{AGRADECIMENTO}

Desejamos externar nossos agradecimentos ao Corpo Docente e à Coordenação do Programa de PósGraduação em Direito da Universidade Federal de Pelotas e ao Programa de Pós-Graduação em Política Social e Direitos Humanos da Universidade Católica de Pelotas pelas contribuições em nossa formação.

Todos os autores declararam não haver qualquer potencial conflito de interesses referente a este artigo. 


\section{REFERÊNCIAS}

ALMEIDA, Gregório de Assagra de. Direito processual coletivo brasileiro: um novo ramo do direito processual. São Paulo: Saraiva, 2003.

ARENHART, Sérgio Cruz. Perfis da tutela inibitória coletiva. São Paulo: Ed. Revista dos Tribunais, 2003.

AZEVEDO. Júlio Camargo de. O microssistema de processo coletivo brasileiro: uma análise feita à luz das tendências codificadoras. Disponível em: http://www.esmp.sp.gov.br/revista_esmp/index.php/R JESMPSP/article/viewFile/43/26 Acesso em: 04 de dezembro de 2018

CAMBI; Eduardo; FOGAÇA; Marcos Vargas. Conversão da ação individual em ação coletiva: análise do conteúdo do artigo 333 do CPC/2015, das razões do veto da Presidente da República e do aproveitamento do instituto no atual sistema processual. Revista brasileira de direito. Disponível em:

https://seer.imed.edu.br/index.php/revistadedireito/art icle/view/1669/1226. Acesso em: 06 de dezembro de 2018

Conselho Nacional de Justiça. Relatório Analítico Propositivo. Justiça Pesquisa: Direitos e Garantias Fundamentais. Ações Coletivas no Brasil: Temas, Atores e Desafios da Tutela Coletiva. Disponível em: http://www.cnj.jus.br/files/conteudo/arquivo/2018/03/ 799b01d7a3f27f85b334448b8554c914.pdf. Acesso em: 06 de dezembro de 2018.

GOBBI, Henrique. Nosso sistema jurídico precisa de um código de processo civil coletivo? Disponível em: https://www.migalhas.com.br/dePeso/16,MI277794,1 01048-

Nosso+sistema+juridico+precisa+de+um+codigo+de +processo+civil+coletivo. Acesso em: 04 de outubro de 2019.

LEONEL. Ricardo de Barros. Manual de Processo Coletivo. Malheiros, 2017.

MANCUSO, Rodolfo de Camargo. Jurisdição Coletiva e coisa julgada. Editora RT, 2007.

MARINONI, ARENHART, MITIDIERO. Curso de Processo Civil. Vol. 3; Editora RT, 2015.
MAZZILLI, Hugo Nigro. O processo coletivo e o novo Código de Processo Civil de 2015. In: I Ciclo de Palestras sobre o Novo Código de Processo Civil, São Paulo: Associação Paulista do Ministério Público, 2015.

PORTO. José Roberto Sotero de Mello. Conversão da ação individual em coletiva no novo CPC: um veto que não se sustenta. Disponível em https://www.conjur.com.br/2016-abr-19/tribunadefensoria-conversao-acao-individual-coletiva-cpc Acesso em: 06 de outubro de 2019.

RAMPIN. Talita Tatiana Dias. A tutela coletiva brasileira: análise dos procedimentos processuais coletivos e das figuras de acionamento judicial. In: Tutela dos fundamentos coletivos, de Yvete Flávio da Costa. São Paulo: Cultura acadêmica, 2011.

SALLES, Carlos Alberto. Políticas Públicas e a legitimidade para a defesa de interesses difusos e coletivos. Disponível em: file:///D:/User/Downloads/SALLES-

CAREPROPolPublelegitimid\%20\%20TEXTO\%20D O\%20SEMIN\%C3\%81RIO\%20(1).pdf. Acesso em 03 de outubro de 2019.

SILVA. RODRIGO EUGÊNIO. A tutela judicial do direito à saúde no Brasil. Niterói, RJ, 2016. Disponível em:

file:///D:/User/Downloads/A\%20Tutela\%20Judicial\% 20do\%20Direito $\% 20 \%$ C $3 \%$ A0\%20Sa\%C3\%BAde\% 20no\%20Brasil\%20(3).pdf. Acesso em 02 de dezembro de 2018.

SILVESTRE, Gilberto Fachetti. NEVES, Guilherme Valli da Moraes; GUSELLA, Gabriela Azeredo. Tutela Processual Coletiva: os impactos e novidades do novo Código de Processo Civil. Anais do II Congresso de Processo Civil Internacional, Vitória, 2017.

TORRES. Artur. A tutela coletiva dos direitos individuais - considerações acerca do Projeto do Novo Código de Processo Civil. Arana, 2013.

ZAVASCKI. Teori Albino. Processo Coletivo Tutela de Direitos Coletivos e Tutela Coletiva de Direitos. Revista dos Tribunais, 2007. 